\title{
ENHANCEMENT OF THE HIGH-TEMPERATURE TENSILE CREEP STRENGTH OF MONOCRYSTALLINE NICKEL-BASE SUPERALLOYS BY PRE-RAFTING IN COMPRESSION
}

\author{
U. Tetzlaff and H. Mughrabi \\ Institut für Werkstoffwissenschaften, Lehrstuhl I, \\ Friedrich-Alexander-Universität Erlangen-Nürnberg, \\ Martensstr. 5, D-91058 Erlangen, F.R. Germany
}

\begin{abstract}
In recent years, the development of $\gamma^{\prime}$-hardened monocrystalline nickel-base superalloys focused on different aspects of alloy composition and microstructural refinement. In particular, the formation of so-called $\gamma / \gamma^{\prime}$-raft structures, lying typically, in the case of a negative $\gamma / \gamma^{*}$-lattice misfit $\delta$, perpendicular to the stress axis during high-temperature tensile creep had attracted much attention. Unfortunately, this microstructural transformation leads in most cases to deteriorated creep properties. Earlier attempts to prevent rafting by suitable prior annealing treatments had been in so far unsuccessful, that while the applied annealing treatment retarded raft formation, it inevitably lead to microstructural coarsening accompanied by creep acceleration. The goal of the present extensive study is to show that suitable pre-rafting in compression, leading to a $\gamma / \gamma^{\prime}$-raft structure parallel to the stress axis in the case of a negative lattice misfit, enhances not only the isothermal hightemperature fatigue strength, as shown earlier, but also the hightemperature creep properties. The observed macroscopic creep behaviour will be discussed with reference of microstructural observations.
\end{abstract}

\section{Introduction}

Monocrystalline nickel-base superalloys, hardened by a high volume fraction (up to ca. $70 \%$ ) of the ordered $\gamma^{2}$-phase ( $\mathrm{Ll}_{2}-$ structure), which is coherently embedded in the fcc $\gamma$-matrix, are widely used as turbine blade material in aircrafts. In these hightemperature materials, so-called rafting (directional coarsening) has emerged as an important phenomenon both in laboratory tests
$[1,2,3]$ and in hot sections of turbine blades subjected to service conditions [4]. Furthermore, rafting has been observed after thermomechanical fatigue (TMF) [5]. A typical feature of the raft formation is, among other parameters, the strong dependence on the sign and magnitude of the applied stress and the $\gamma / \gamma^{\prime}$-lattice mismatch $\delta=2\left(a_{\gamma}-a_{\gamma}\right) /\left(a_{\gamma}+a_{\gamma}\right)$, where $a_{\gamma^{\prime}}$ and $a_{\gamma}$ are the lattice parameters of the phases $\gamma^{\prime}$ and $\gamma$, respectively. In the commonly used commercial nickel-base superalloys, the lattice mismatch is negative, and an external stress in tension (compression) produces a raft-like structure perpendicular (parallel) to the [001]-stress axis. The earliest model explaining this observation is due to Pineau [6]. According to the current understanding, which has been recently reviewed by Nabarro [7], the driving force for rafting, which is promoted by the combined action of dislocation activity and diffusion, stems from the fact that the superposition of the external stress and the coherency stresses introduces a gradient in elastic strain energy between the two types of $\gamma$-channels, which lie perpendicular and parallel to [001], respectively.

Since rafting was also detected in turbine blades subjected to service conditions $[4,8]$, it was of considerable interest to study the effect of this modified microstructure on the fatigue and creep strengths. Therefore, Ott et al. $[9,10]$ studied systematically the effect of pre-rafting on the isothermal fatigue behaviour of the alloys CMSX-6 and CMSX-4. For this purpose, they introduced raft structures parallel (by pre-rafting in compression) and perpendicular (by pre-rafting in tension) into the specimens by a small creep deformation $(\leq 0.4 \%)$ prior the fatigue tests. A typical result of this work is shown in Fig. 1 (stress amplitude $\Delta \sigma / 2$ versus number of cycles $\mathrm{N}$ ). 


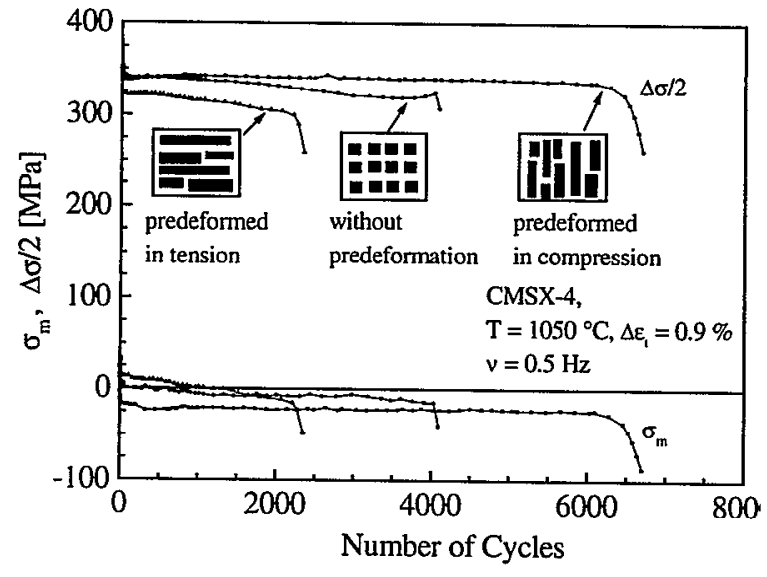

Fig. 1: Cyclic deformation curves of CMSX-4 crystals with the original cuboidal $\gamma^{\prime}$-precipitates and after pre-rafting by tensile or compressive crecp at $1050^{\circ} \mathrm{C}[9,10]$. The initial nicrostructures are indicated schematically.

After an initial weak cyclic softening, the cyclic deformation curves show almost steady-state deformation until failure. The most important result is that while the specimens with the raft structure parallel to the stress axis exhibited the longest fatigue life, the specimens with the raft structure perpendicular to the stress axis showed the shortest fatigue life. The fatigue lives of the specimens with cuboidal $\gamma^{\prime}$-particles were intermediate between these to extremes. It should be noted that the prior creep deformation induced mean stresses $\sigma_{\mathrm{m}}$ in the sense of the pre-deformation. In separate tests, it could be shown that whilc these mean stresses affected the fatigue behaviour, the basic result remained unaffected, when these mean stresses were compensated.

Over the last three decades, the effects of rafting on the creep behaviour have been discussed controversially in a number of papers $[2,7,11,12,13,14]$. It has to be mentioned that, in these investigations, all raft structures formed during tensile creep (for $\delta<0)$ and were oriented perpendicular to the stress axis.

In modern monocrystalline nickel-base superalloys with low negative misfit, such as SRR 99, CMSX-6, CMSX-4, rafting perpendicular to the stress axis causcs under most experimental conditions a deterioration of the creep strength $[2,15,16]$. On the other hand, several authors suggest that a raft structure perpendicular to the stress axis can, under the condition of high temperatures and very low stresses, lead to an increase of the creep strength $[2,7,13,17,18]$, as long as cutting of the rafts, which seems to be facilitated compared to cuboidal $\gamma / \gamma^{\prime}$-microstructures, is avoided. In these cases, it is assumed, that under these conditions a raft structure becomes an effective barrier against dislocation by-passing by glide-climb motion along the $\gamma / \gamma^{\prime}$-interfaces. Investigations of one-step heat treated SRR 99 specimens showed this behaviour in the case of very low stresses and a comparably high temperature $[18,19]$. Nevertheless, to the authors' knowledge, detailed experimental investigations of modern two-step annealed nickel-base superalloys, comparing well-aligned $\gamma^{\prime}$ cuboids with pre-rafted material perpendicular to the stress axis, are still missing. A reason for this might be that rafting is unavoidable during service and therefore accepted as a fact of life.
For alloys with high negative misfit, improvements of the creep strength due to the formation of raft structures perpendicular to the stress axis have been found experimentally $[20,21]$. Pearson et al. [21] presented experimental evidence showing that a pre-rafted structure perpendicular to the stress axis, consisting of finely spaced $\gamma / \gamma^{\prime}$-lamellas, enhances the creep strength remarkably. They concluded that for high temperatures and low stresses the operative creep mechanism involves dislocation motion primarily in the $\gamma$-phase with mobile dislocations circumventing or bypassing the $\gamma^{\prime}$-phase by a combined glide and climb process, as firstly discussed by Carry and Strudel [22]. In an ideal situation, with $\gamma^{\prime}$-rafts extending from one side of the crystal to the other in an almost perfectly regular manner, gliding/climbing around it by matrix dislocations is impossible. This conclusion is in accordance with opinions of other authors $[1,13,21,23,24]$. Another example for enhanced creep properties due to tensile pre-rafting can be found in [25]. In contrast, for lower temperatures and higher stresses, the same material used in [25], which had been pre-rafted in tension, exhibited a reduced crecp strength after pre-rafting in tension, due to easier dislocation cutting of the $\gamma^{\prime}$-rafts [26].

Summarising the observations on the creep strength of specimens with rafts perpendicular to the stress axis in material with high and low negative misfit, it can be proposed that rafts perpendicular to the stress axis may possibly have a higher potential for improving the creep strength in material with a high negative misfit, because the mobility and therefore the possibility for cutting of the rafts is reduced due to a smaller $\gamma$-channel width and more stabilised $\gamma / \gamma^{\prime}$ interfaces consisting of finely spaced dislocation networks. Irrespective of these considerations, the formation of raft structures perpendicular to the stress axis leads in most cases to reduced creep properties and in all cases reported so far $[9,10]$ to a reduced fatigue life. Therefore, it is concluded that pre-rafting in tension provides no promising potential for microstructural development.

The aim of the present work is to point out that suitable pre-rafting in compression not only improves the fatigue life, as reported earlier $[9,10,27,28]$, but can also enhance significantly the creep strength of commercial monocrystalline superalloys, as suggested previously [10] and reported recently $[28,29]$.

\section{Theoretical background}

In order to understand how different initial microstructures affect the creep behaviour, some simple theoretical considerations are helpful. The following deformation mechanisms are discussed:

\section{- Circumvention of the $\gamma^{3}$-particles by climb \\ - Circumvention of the $\gamma^{\prime}$-particles by the Orowan mechanism \\ - Cutting of the $\gamma^{\prime}$-particlcs}

Firstly, we should consider the combined glide-climb motion along the $\gamma / \gamma^{\prime}$-interface [30] in the spirit of the classical work by Carry and Strudel [22], which is dominant in the regime of low stresses and high temperatures, provided the threshold stresses for other mechanisms like the cutting or the circumvention of the $\gamma^{\prime}$ particles by Orowan bowing are not exceeded.

According to calculations of both von Mises stresses $[30,31,32]$ and the more realistic pertinent resolved shear stresses [30] as well 
as experimental observations $[2,3,14,16]$, the largest local (shear) stresses develop in the case of an applied tensile load, initially in the $\gamma$-channels which lie perpendicular to the stress axis. Thus, tensile plastic yielding starts first in the horizontal $\gamma$-channels, whereas the dislocations are stopped after glide at the $\gamma / \gamma^{\prime}$ interfaces (Fig. 2).

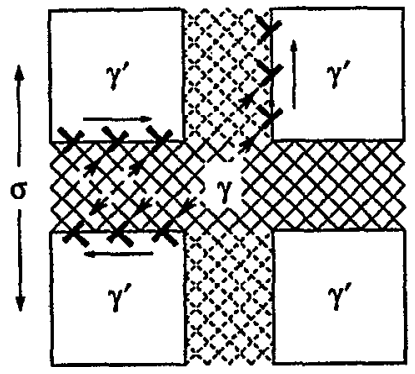

Fig. 2: Schematical drawing of dislocation accumulation and combined glide-climb motion of interfacial dislocations at $\gamma / \gamma^{\prime}$ interfaces. The inclined lines represent the traces of slip planes, dashed lines indicate limited dislocation activity. The arrows parallel to the $\gamma / \gamma$-interfaces indicate the direction of the glideclimb movement of dislocations. After [30].

The arrested interfacial dislocations whose Burgers vectors lie oblique to the $\gamma / \gamma^{\prime}$-interface can move towards the edges of the $\gamma^{\prime}$ particles by a combined glide-climb process, as originally suggested by Carry and Strudel [22]. In a next step, those dislocations which have reached the edge of the $\gamma$ '-particle can glide across the vertical channel and build a dislocation arrangement at the vertical $\gamma / \gamma^{\prime}$-interface, provided the local stresses are large enough. Those dislocations which are arrested at the vertical $\gamma / \gamma^{\prime}$-interface can then move upwards in a similar manner by a combined climbglide process toward the edge of the $\gamma^{\prime}$-particle, and then glide into the next horizontal $\gamma$-channel, etc.

The authors propose, as in $[22,30]$, that the climb process at the $\gamma / \gamma^{2}$-interfaces becomes the strain-rate controlling mechanism.

It is of considerable interest to understand to what extent the $\gamma / \gamma^{\prime}$ raft structures influence the creep properties. We approach this problem by calculating both the horizontal and the vertical climb components of the Peach-Koehler force acting on the arrested interface dislocations in the horizontal $(001)$ and the vertical $(100) /(010)$ planes, respectively [29]. (The stress axis is assumed to lie in the [001] direction.) The Peach-Koehler force is given by

$$
\vec{F}=(\bar{\sigma} \cdot \vec{b}) \times \vec{s}
$$

where $\overline{\bar{\sigma}}$ is the stress tensor; $\vec{b}$ the Burgers vector and $\vec{s}$ the line direction.

It should be noted that in the Peach-Koehler formula, the stress tensor is the result of the superposition of the externally applied stress and the internal (coherency) stresses. During creep, this stress tensor can be modified by dislocation arrangements like networks which relax or increase the internal stresses. Further- more, in these calculations it was assumed that only those dislocation segments which are arrested at the $\gamma / \gamma^{\prime}$-interface after glide on an $a / 2<110>\{111\}$ glide system contribute to the crecp process. Based on geometric considerations, it is sufficient to examine only one plane of the $\{111\}$ plane family, for example the (111) plane. On this plane, six Burgers vectors are possible: $\pm a / 2[01 \overline{1}]$, $\pm a / 2[10 \overline{1}]$ and $\pm a / 2[1 \overline{1} 0]$. Considerations of the Schmid factor show that the slip systems with a Burgers vector $\pm a / 2[1 \overline{1} 0]$ are not activated. For geometrical reasons, the Burgers vectors $\pm a / 2[01 \overline{1}]$ and $\pm \mathbf{a} / 2[10 \overline{1}]$ are equivalent. Therefore, the calculations are only performed for dislocations with the $\pm a / 2[01 \overline{1}]$ Burgers vector on the (111)-plane. The geometry of the glide plane intersecting the $\gamma / \gamma$ '-interfaces determines the line direction of the arrested dislocation segments [33]. Thus, dislocations with a $\pm a / 2[01 T]$ Burgers vector at the (001)- $\gamma / \gamma^{\prime}$-interface result in a $[1 \overline{1} 0]$ line direction $\left(60^{\circ}\right.$-dislocation) at the $(010)$ interface in a [10T] line direction (60 $60^{\circ}$-dislocation) and for the (100)-interface in a [01 1$]$ line direction (pure screw). The screw dislocations do not contribute to the climb process.

Finally, after inserting the parameters discussed above in the Peach-Koehler formula, it follows that the climb force component in the horizontal channels acting in the appropriate directions in the horizontal (001) plane is higher than the climb force component in the vertical channels in the appropriate directions in the (100) or (010) planes [29]. Thus, the circumvention of $\gamma^{\prime}$ plates/particles by dislocation glide-climb motion along the corresponding $\gamma / \gamma$ interfaces is always easier for glide-climb motion along the horizontal (001) than along the vertical (010) or (100) interfaces. Therefore, it is proposed that the raft structure parallel to the stress axis should increase the creep strength compared to the initial cuboidal $\gamma / \gamma^{\prime}$-microstructure or to a raft structure perpendicular to the stress axis, because the raft structure parallel to the stress axis provides the largest areas of vertical interfaces, where the climb process is impeded most strongly. Moreover, the raft structure parallel to the stress axis has only small areas of $\gamma / \gamma^{\prime}$ interfaces perpendicular to the stress axis, where climb is more rapid.

\section{Experimental}

In the present study, rods of the two-step annealed $\gamma^{\prime}$-hardened nickel-base superalloy SRR 99 with orientations, lying within $5^{\circ}$ of [001], were used. The crystal orientations were determined by the Laue back reflection technique. The composition of the alloy is listed in Table 1:

Table 1: Composition of SRR 99.

\begin{tabular}{|c|c|c|c|c|c|c|}
\hline Element & $\mathrm{C}$ & $\mathrm{Si}$ & $\mathrm{Mn}$ & $\mathrm{Cr}$ & $\mathrm{Mo}$ & $\mathrm{Co}$ \\
\hline Wt.\% & 0.01 & $<0.1$ & $<0.1$ & 8.6 & $<0.03$ & 5.02 \\
\hline Element & $\mathrm{Ti}$ & $\mathrm{Al}$ & $\mathrm{Fe}$ & $\mathrm{B}$ & $\mathrm{Cu}$ & $\mathrm{S}$ \\
\hline Wt.\% & 2.22 & 5.61 & 0.03 & $<0.0013$ & $<0.03$ & 0.0006 \\
\hline Element & $\mathrm{Zr}$ & $\mathrm{W}$ & $\mathrm{V}$ & $\mathrm{P}$ & $\mathrm{Ta}$ & $\mathrm{Ni}$ \\
\hline Wt.\% & $<0.005$ & 9.66 & $<0.03$ & $<0.005$ & 2.83 & bal. \\
\hline
\end{tabular}


After machining and electropolishing of the surface, the specimen had a gauge length of $12 \mathrm{~mm}$ and a diameter of $9 \mathrm{~mm}$. The initial $\gamma / \gamma^{\prime}$-microstructure consisted of fairly regularly aligned cuboidal $\gamma^{\prime}$ particles with a $\gamma^{\prime}$ edge length of $0.44 \mu \mathrm{m}$ and a volume fraction of $72 \%$. The constrained misfit was determined by high resolution $\mathrm{X}$-ray diffraction as $\delta \approx 1.4 \times 10^{-3}$.

The creep tests were performed on a servohydraulic test machine (MTS 880). For the investigations, a raft structure parallel to the stress axis was produced by pre-deformation in compression at a stress $\sigma$ of $-120 \mathrm{MPa}$ and a temperature $\mathrm{T}$ of $1050^{\circ} \mathrm{C}$. The required plastic creep strains were small and less than $0.4 \%$, to avoid prior damaging. For the verifying creep experiments, different applied stresses (150 to $300 \mathrm{MPa}$ ) and constant temperatures of $1000^{\circ} \mathrm{C}$ and $1050^{\circ} \mathrm{C}$ were chosen. The deformed samples were investigated by scanning electron microscopy (SEM) as well as by transmission electron microscopy (TEM).

\section{Results and Discussion}

\section{Creep at $1000^{\circ} \mathrm{C}$}

In this section, tensile creep curves (tensile plastic creep strain $\varepsilon_{\mathrm{pl}}$ versus creep time t) are compared for specimens with the initial cuboidal $\gamma$ '-structure and the raft structure parallel to the stress axis for creep tests at different applied stresses (150-300 MPa) and a temperature of $1000{ }^{\circ} \mathrm{C}$. These tests were limited to plastic strains of $3 \%$, since larger strains are not tolerable in a component. The discussion of the macroscopic behaviour will be based on microstructural features.

Fig. 3. shows tensile creep curves $\left(\sigma=150 \mathrm{MPa}, \mathrm{T}=1000^{\circ} \mathrm{C}\right)$ of two specimens in the as-aged condition and after pre-rafting in compression.

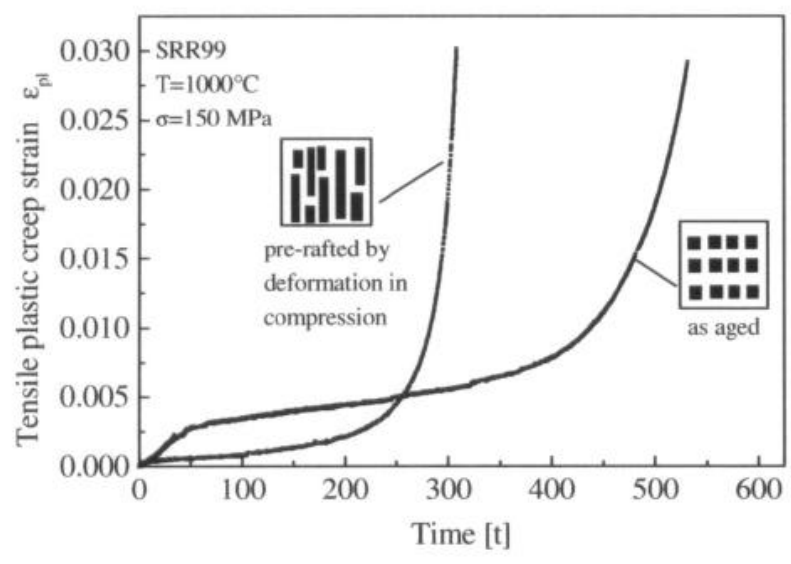

Fig. 3: Tensile creep curves $\left(\sigma=150 \mathrm{MPa}, \mathrm{T}=1000^{\circ} \mathrm{C}\right)$ up to $3 \%$ plastic strain of two monocrystalline SRR 99 specimens in the asaged condition and after pre-rafting in compression, respectively.
It is obvious that up to a certain value of plastic creep strain the initially pre-rafted specimen shows a considerably enhanced creep strength compared to the specimens with the initial cuboidal $\gamma / \gamma^{\prime}$ microstructure. This experimental result agrees with the conclusion of the previous theoretical considerations of the PeachKoehler calculations, according to which rafts lying parallel to the stress axis should reduce the creep rate, if the climb at the $\gamma / \gamma^{\prime}$ interfaces becomes the rate-determining process. In TEMinvestigations of the two specimens after $3 \%$ plastic creep strain, this result could be confirmed in as much as that no cutting of the $\gamma^{\prime}$-phase by dislocations could be found. After a creep time of approximately $260 \mathrm{~h}$, the creep curves of the specimens with the initial cuboidal $\gamma^{\prime}$ and with the raft structure cross. This macroscopic behaviour can be explained through microstructural observations (see Fig. 4).

In the specimen with the initial cuboidal $\gamma^{\prime}$-particles, a transformation to the typical (unfavourable) raft structure perpendicular to the stress axis occurs, as discussed before. On the other hand, the microstructure of the specimens with the initial well-aligned raft structure parallel to the stress axis develops into a rather irregular $\gamma / \gamma^{\prime}$-microstructure, associated with the observed enhanced creep rate. It is evident that during tensile creep a raft structure parallel to the stress axis is energetically not as favourable as a $\gamma^{\prime}$ raft structure perpendicular to the stress axis. Therefore, the initial raft structure parallel to the stress axis tends to transform into a raft structure perpendicular to the stress axis. This transformation is, however, not completed within a plastic creep strain of only $3 \%$.
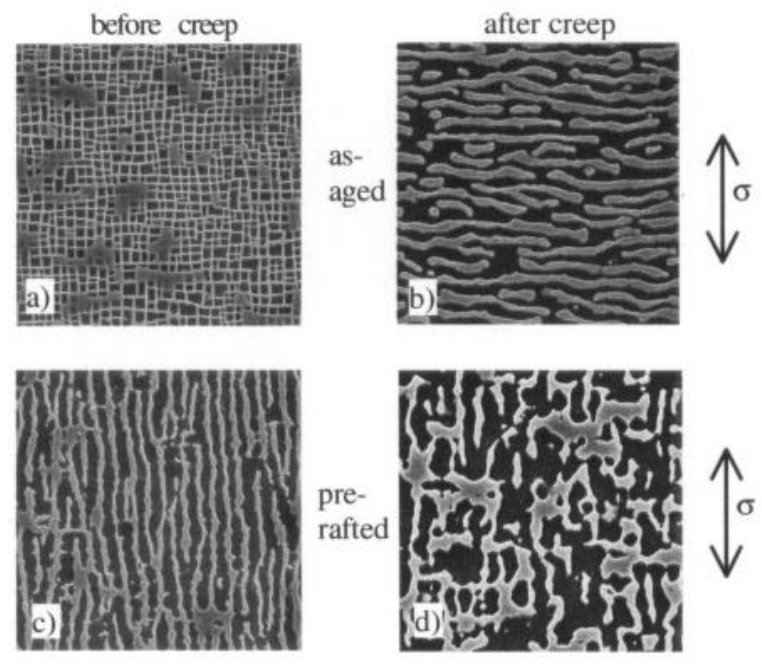

$5 \mu \mathrm{m}$

Fig. 4: SEM-micrographs of the microstructures in the initial state and after tensile deformation $\left(\sigma=150 \mathrm{MPa}, \mathrm{T}=1000^{\circ} \mathrm{C}\right)$ a) asaged b) as-aged, after $3 \%$ plastic creep strain in tension c) prerafted in compression d) pre-rafted in compression, after $3 \%$ plastic creep strain in tension. 


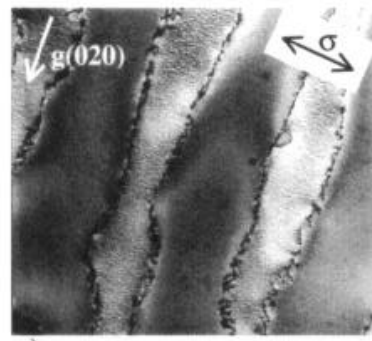

a)

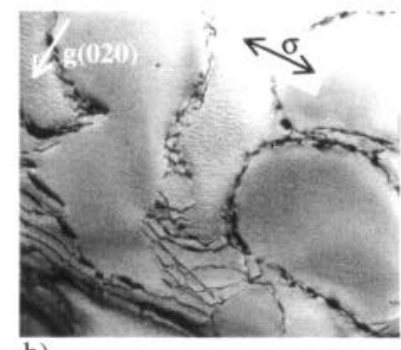

b)
$400 \mathrm{~nm}$

Fig. 5: TEM-microcraphs of (010)-sections after tensile creep deformation at $\sigma=150 \mathrm{MPa} / \mathrm{T}=1000^{\circ} \mathrm{C}$. a) as-aged b) pre-rafted in compression.

At an increased stress of $200 \mathrm{MPa}$, pre-rafting in compression improves the tensile creep properties even more strongly, as shown in Fig. 6.

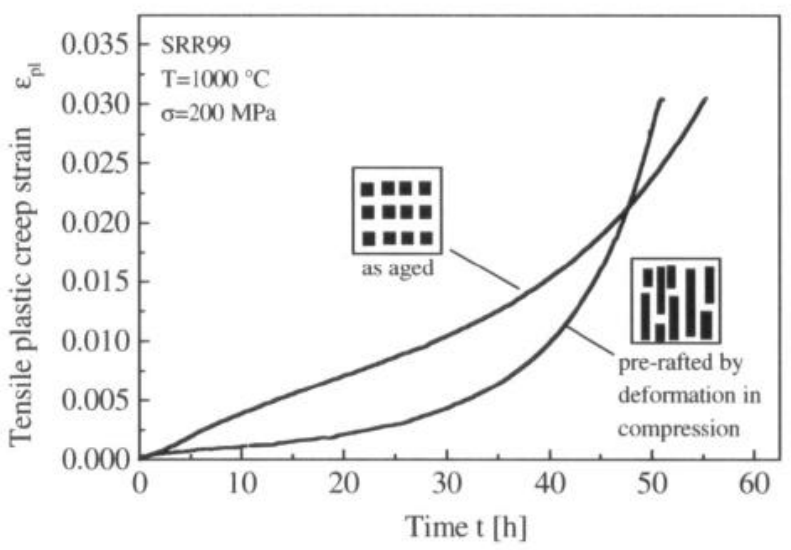

Fig. 6: Tensile creep curves $\left(\sigma=200 \mathrm{MPa}, \mathrm{T}=1000{ }^{\circ} \mathrm{C}\right)$ up to $3 \%$ plastic strain of two monocrystalline SRR 99 specimens in the asaged condition and after pre-rafting in compression, respectively.

As shown in Fig. 6, the creep strength of the specimen consisting of a raft structure parallel to the stress axis is improved appreciably up to a tensile plastic strain of about $2 \%$, compared to the specimen with the initial cuboidal $\gamma / \gamma^{\prime}$-microstructure. This improvement can be interpreted in the same manner as the creep experiments at $150 \mathrm{MPa}$, namely that climb as the rate-controlling process is remarkably impeded for a raft structure, which consists mainly of $\gamma / \gamma^{\prime}$-interfaces parallel to the stress axis. At larger strains, however, this behaviour is reversed. Microstructural investigations (Fig. 7), show as for to the creep experiments performed at $150 \mathrm{MPa}$, that the enhanced creep rate for the specimen with the raft structure parallel to the stress is closely connected to the formation of an irregular $\gamma / \gamma^{\prime}$-microstructure, providing deformation paths for facilitated glide and climb [13,24]. Due to the shorter creep times at $200 \mathrm{MPa}$, compared to $150 \mathrm{MPa}$, the relative time available for coarsening from a raft structure parallel to the stress axis toward a more stable raft configuration perpen- dicular to the stress axis is reduced. Consequently the creep range of enhanced creep properties for the raft structure parallel to the stress is extended. This behaviour indicates that the processes of directional coarsening discussed here are more time-dependent than stress-dependent [12]. By contrast, the specimen with the initial cuboidal $\gamma / \gamma^{\prime}$-microstructure transforms immediately into a well-aligned raft structure perpendicular to the stress axis. TEMinvestigations of both specimens after $3 \%$ plastic creep strain show that cutting of the $\gamma^{\prime}$-phase as a competing deformation mechanism can be excluded.
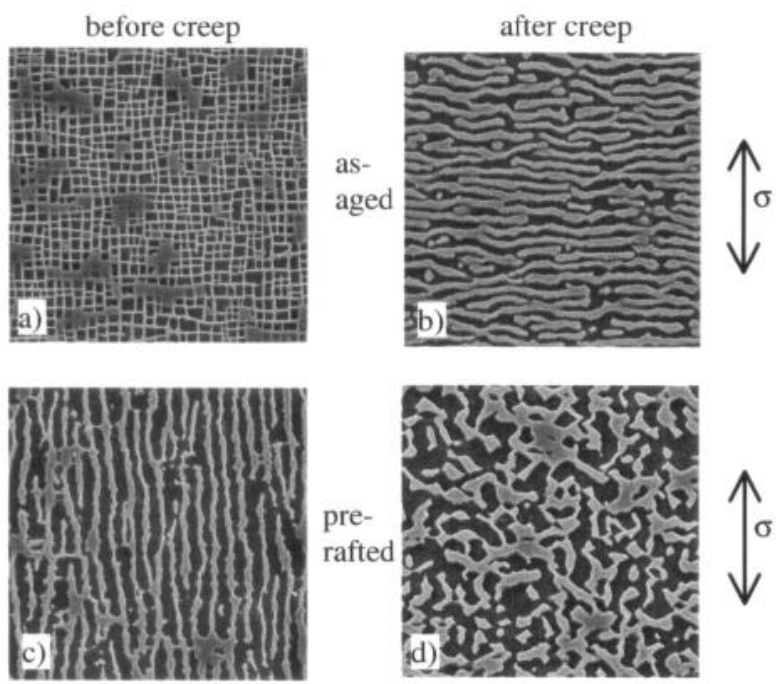

$5 \mu \mathrm{m}$

Fig. 7: SEM-micrographs of the microstructures in the initial state and after tensile deformation $\left(\sigma=200 \mathrm{MPa}, \mathrm{T}=1000^{\circ} \mathrm{C}\right)$ a) asaged b) as-aged, after $3 \%$ plastic creep strain in tension c) prerafted in compression d) pre-rafted in compression, after $3 \%$ plastic creep strain in tension.

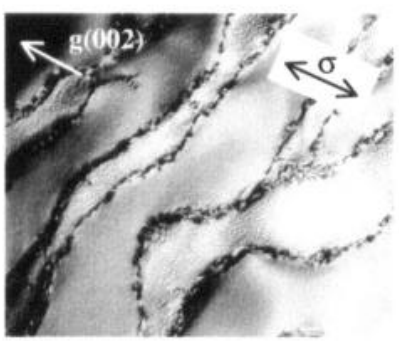

a)

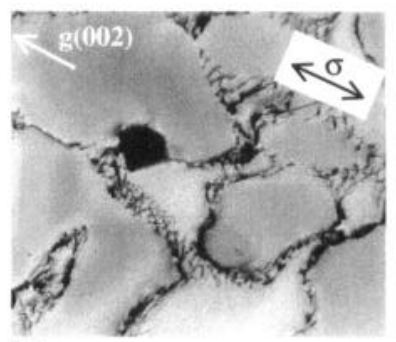

b)
$400 \mathrm{~nm}$

Fig. 8: TEM-microcraphs of (010)-sections after tensile creep deformation at $\sigma=200 \mathrm{MPa} / \mathrm{T}=1000^{\circ} \mathrm{C}$. a) as-aged b) pre-rafted in compression.

At an even higher applied stress of $300 \mathrm{MPa}$, the creep behaviour of the specimen with a rafted structure parallel to the stress axis is significantly changed, compared to the creep test at 150 and 200 MPa (Fig. 9). 


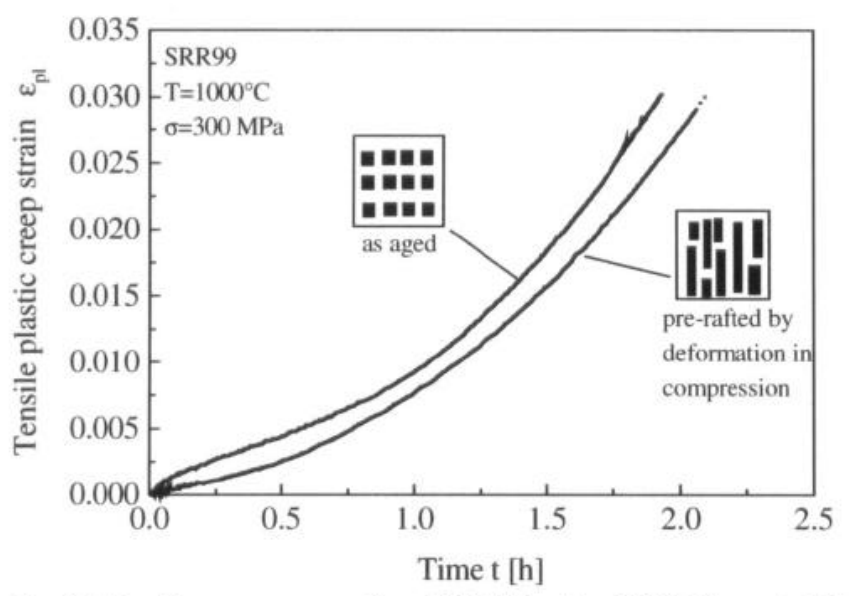

Fig. 9: Tensile creep curves $\left(\sigma=300 \mathrm{MPa}, \mathrm{T}=1000^{\circ} \mathrm{C}\right)$ up to $3 \%$ plastic strain of two monocrystalline SRR 99 specimens in the asaged condition and after pre-rafting in compression, respectively.

As shown in Fig. 9, the rafted structure parallel to the stress axis exhibits improved creep properties over the whole creep time.

Taking into account the microstructural investigations, it is obvious that the initial cuboidal $\gamma / \gamma^{\prime}$-microstructure transforms immediately towards a raft structure perpendicular to the stress axis. More important, the initial pre-rafted structure parallel to the stress axis shows coarsening effects, but remains elongated parallel to the stress axis. Obviously, in this particular case, the time available for diffusion-controlled transformation of the initial raft structure parallel to the stress axis into an irregular $\gamma / \gamma^{\prime}$ microstructure is too short; thus no crossing of the two creep curves can be observed. In fact, after $3 \%$ plastic strain, TEMinvestigations revealed cutting of the $\gamma^{\prime}$-particles in both types of initial $\gamma / \gamma^{\prime}$-microstructures. Combining the microstructural observations and the macroscopic creep behaviour, it can be assumed that, in the beginning of the creep experiments, dislocation climb motion along the $\gamma / \gamma^{\prime}$-interfaces controls the deformation rate. Furthermore, after successive strain hardening, when the sum of the external stress and the deformation-induced forward stress in the hard $\gamma^{\prime}$-particles exceeds the local flow stress of the $\gamma$ particles, the ordered $\gamma^{\prime}$-particles will be cut by dislocations. Thus, in a later stage of creep, cutting of the $\gamma^{\prime}$-particles and the circumvention of the $\gamma^{\prime}$-particles are competitive mechanisms controlling the creep rate.
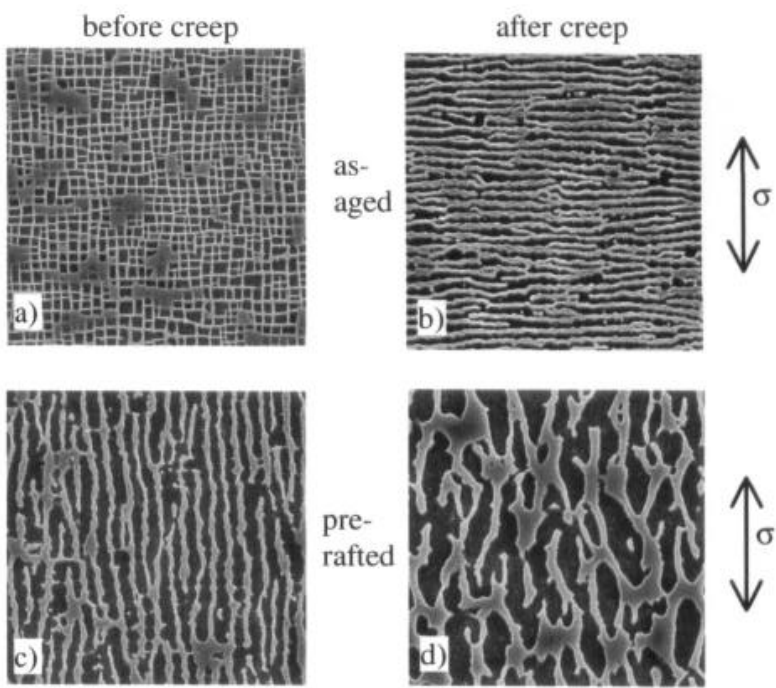

$5 \mu \mathrm{m}$

Fig. 10: SEM-micrographs of the microstructures in the initial state and after tensile deformation $\left(\sigma=300 \mathrm{MPa}, \mathrm{T}=1000{ }^{\circ} \mathrm{C}\right)$ a) as-aged b) as-aged after $3 \%$ plastic creep strain in tension c) pre-rafted in compression d) pre-rafted in compression, after $3 \%$ plastic creep strain in tension.

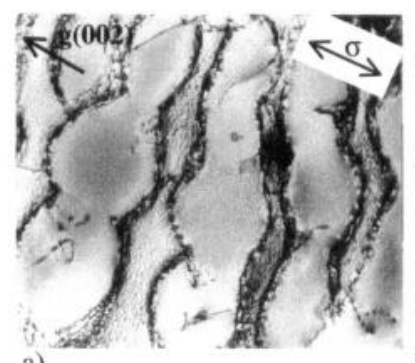

a)

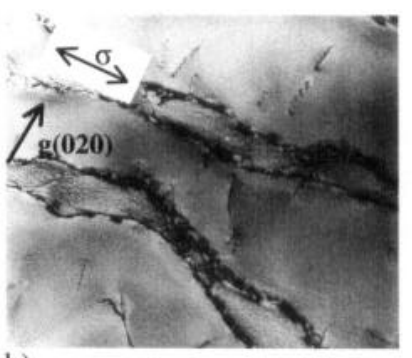

b)
Fig. 11: TEM-microcraphs of (010)-sections after tensile creep deformation at $\sigma=300 \mathrm{MPa} / \mathrm{T}=1000^{\circ} \mathrm{C}$. a) as-aged b) pre-rafted in compression. 


\section{Creep at $1050^{\circ} \mathrm{C}$}

At an applied stress of $150 \mathrm{MPa}$, pre-rafting in compression leads to an improvement of the tensile creep properties, compared to the initial cuboidal $\gamma / \gamma^{\prime}$-microstructure (see Fig. 12).

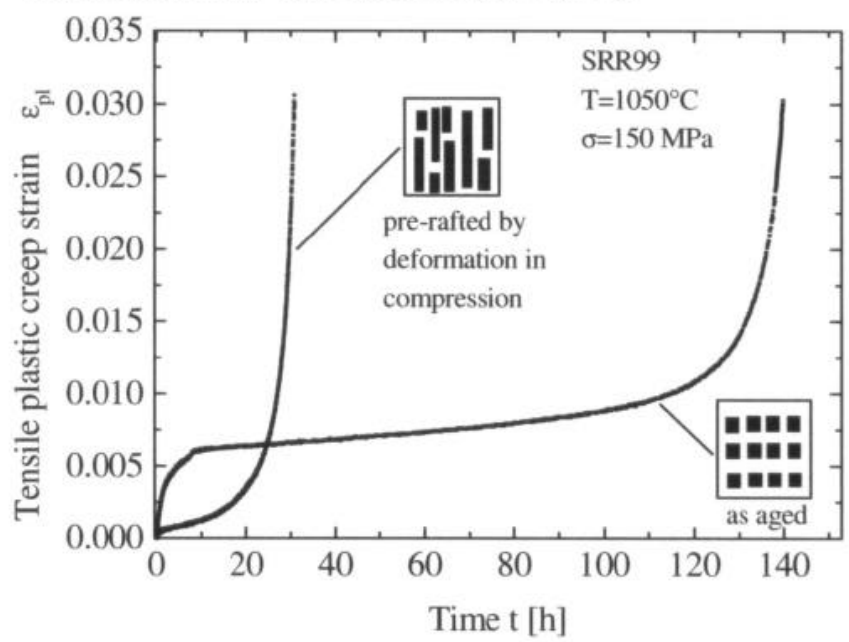

Fig. 12: Tensile creep curves $\left(\sigma=150 \mathrm{MPa}, \mathrm{T}=1050^{\circ} \mathrm{C}\right)$ up to $3 \%$ plastic strain of two monocrystalline SRR 99 specimens in the as-aged condition and after pre-rafting in compression, respectively.

This improvement by pre-rafting in compression can be attributed to the reduced climb force acting at the vertical $\gamma / \gamma^{\prime}$-interfaces as discussed for creep at $1000^{\circ} \mathrm{C}$.
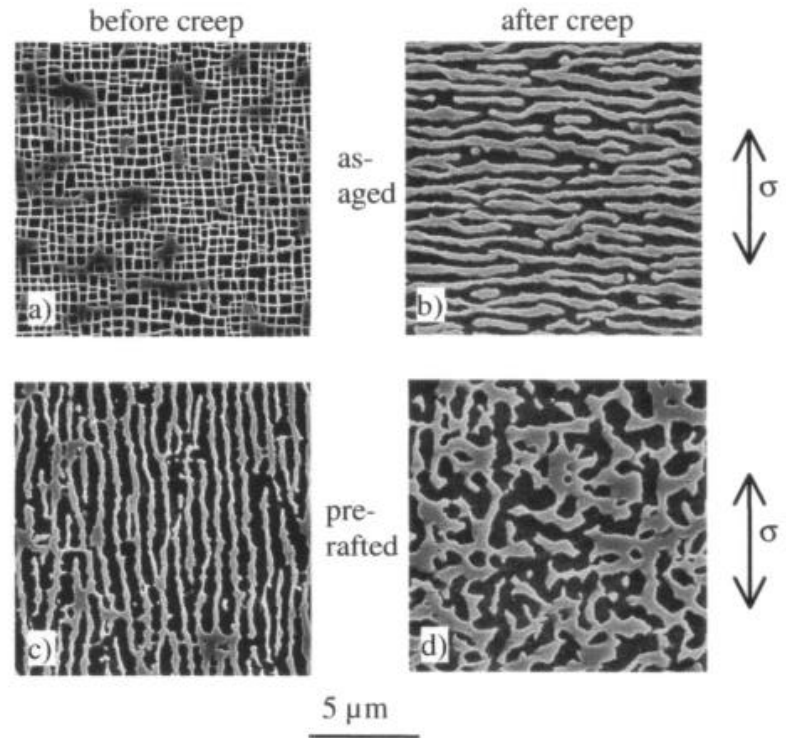

Fig. 13: SEM-micrographs of the microstructures in the initial state and after tensile deformation $\left(\sigma=150 \mathrm{MPa}, \mathrm{T}=1050^{\circ} \mathrm{C}\right)$ a) as-aged b) as-aged after $3 \%$ plastic creep strain in tension c) pre-rafted in compression d) pre-rafted in compression, after 3\% plastic creep strain in tension.
After a relatively short creep time, this behaviour is reversed. Comparing these creep experiments $\left(\sigma=150 \mathrm{MPa}, \mathrm{T}=1050^{\circ} \mathrm{C}\right)$ with the creep experiments performed at the same applied stress of $150 \mathrm{MPa}$ but at a lower temperature of $1000^{\circ} \mathrm{C}$, the pronounced rapid increase of the creep rate at $1050^{\circ} \mathrm{C}$ is undoubtedly related to the facilitated diffusion-controlled transformation of the initial raft structure parallel to the stress axis to an irregular $\gamma / \gamma^{\prime}$ microstructure at this higher temperature. This microstructural transformation is evident from Fig. 13 after 3\% plastic creep strain.

Furthermore, TEM-investigations reveal that under these conditions $\left(\sigma=150 \mathrm{MPa}, \mathrm{T}=1050^{\circ} \mathrm{C}\right)$, both types of initial $\gamma / \gamma^{\prime}$ microstructure show, in contrast to the test at same applied stress at $1000^{\circ} \mathrm{C}$, cutting of the $\gamma^{\prime}$-phase by dislocations (Fig. 13). Thus, it can be concluded that cutting of the $\gamma^{\prime}$-phase depends not only on the residual stresses but also on the temperature [15].

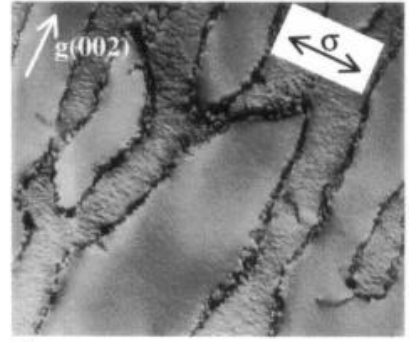

a)

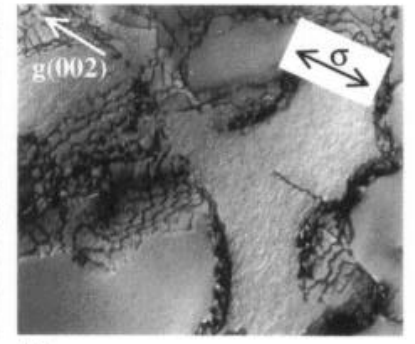

b)
$400 \mathrm{~nm}$

Fig. 14: TEM-microcraphs of (010)-sections after tensile creep deformation at $\sigma=150 \mathrm{MPa} / \mathrm{T}=1050^{\circ} \mathrm{C}$. a) as-aged b) pre-rafted in compression.

At a higher applied stress of $200 \mathrm{MPa}$, a basically similar creep behaviour as discussed for a stress of $150 \mathrm{MPa}$ is found (Fig. 15), the main difference being that the time at which the two creep curves cross is now shorter than at the lower stress (Fig. 12).

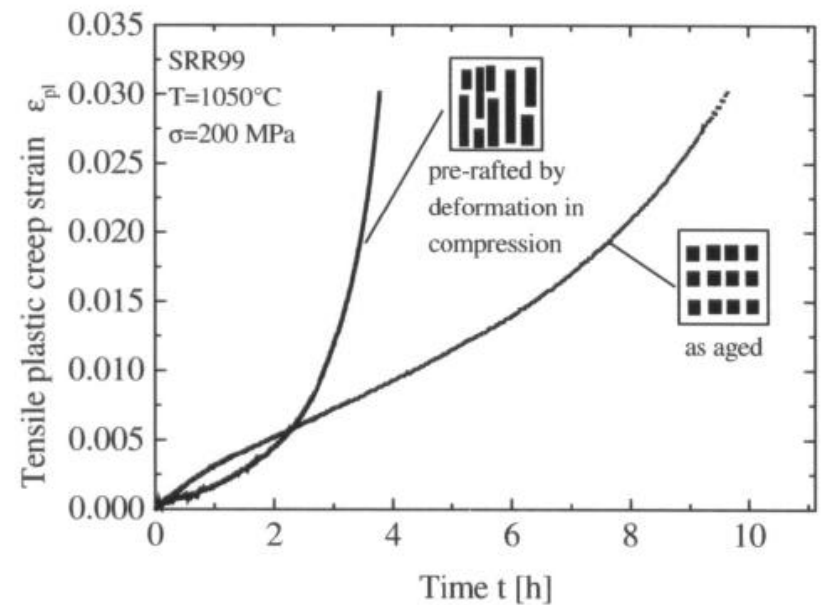

Fig. 15: Tensile creep curves $\left(\sigma=200 \mathrm{MPa}, \mathrm{T}=1050^{\circ} \mathrm{C}\right)$ up to $3 \%$ plastic strain of two monocrystalline SRR 99 specimens in the as-aged condition and after pre-rafting in compression, respectively. 
Subsequently, as in the previous examples, the behaviour of the initially pre-rafted specimen shows an enhanced creep rate, when the formation of an irregular $\gamma / \gamma^{\prime}$-microstructure sets in (Fig. 16).
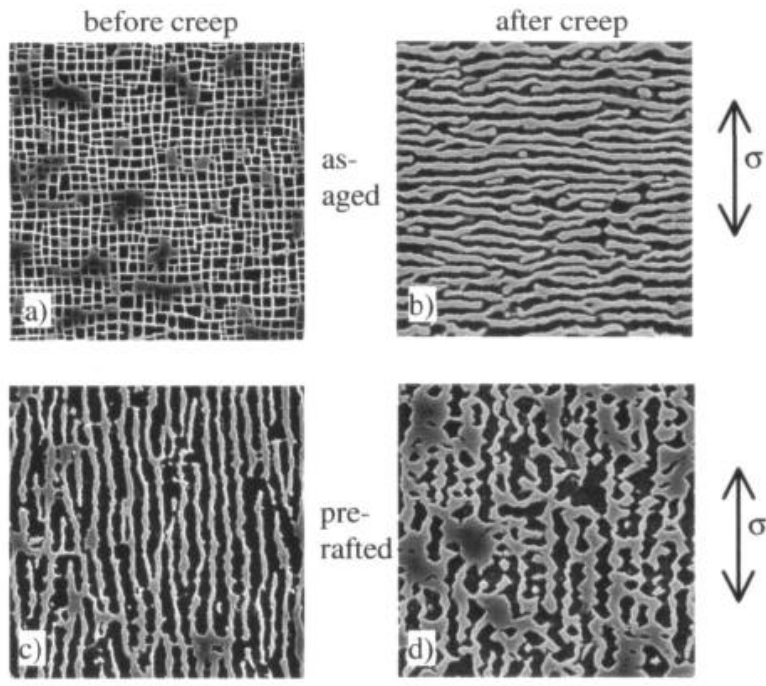

$$
5 \mu \mathrm{m}
$$

Fig. 16: SEM-micrographs of the microstructures in the initial state and after tensile deformation $\left(\sigma=200 \mathrm{MPa}, \mathrm{T}=1050^{\circ} \mathrm{C}\right)$ a) as-aged b) as-aged after $3 \%$ plastic creep strain in tension c) pre-rafted in compression d) pre-rafted in compression, after $3 \%$ plastic tensile creep strain.

Here, it should be noted that the increased applied stress of 200 MPa results in enhanced cutting of the $\gamma^{\prime}$-phase by dislocations for both initial $\gamma / \gamma^{\prime}$-microstructures. As shown in Fig. 17, cutting of the $\gamma^{\prime}$-phase is less pronounced for the initial cuboidal $\gamma / \gamma^{\prime}$ microstructure which coarsened directly to an almost perfect raft structure perpendicular to the stress axis than for the initial raft structure parallel to the stress axis which transformed into an irregular raft structure. This experimental finding is in accordance with opinions of some authors [15,34], who pointed out that enhanced inhomogenity of the local deformation in irregularly shaped $\gamma / \gamma^{\prime}$-microstructures leads to increased cutting of the $\gamma^{\prime}$ particles by dislocations.
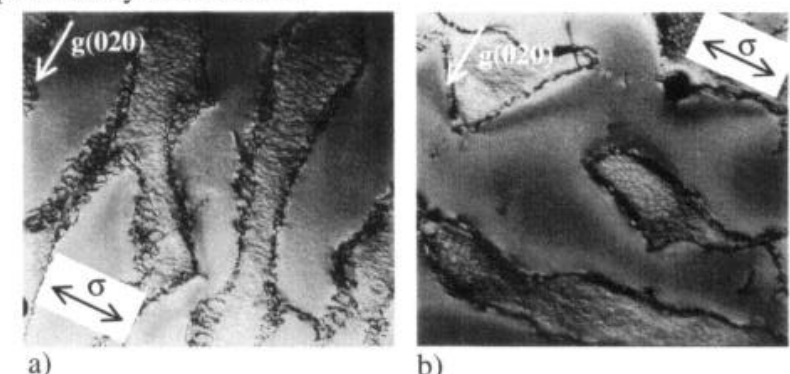

b)

$\underline{400 \mathrm{~nm}}$

Fig. 17: TEM-microcraphs of (010)-sections after tensile creep deformation at $\sigma=200 \mathrm{MPa}, \mathrm{T}=1050^{\circ} \mathrm{C}$ a) as-aged b) pre-rafted in compression.

\section{Influence of pre-rafting in compression on the minimum creep rate}

In Fig. 18, a Norton-Plot of the minimum plastic creep rate $\dot{\varepsilon}_{p l \text { min }}$ versus $\sigma$ shows for all creep experiments presented previously a remarkable reduction of the minimum creep rate for the initial raft structure parallel to the stress axis, compared to the initial cuboidal $\gamma / \gamma^{\prime}$-microstructure. Only in one particular case at a temperature of $1050^{\circ} \mathrm{C}$ and an applied stress of $\sigma=150 \mathrm{MPa}$, the minimum creep rate was not reduced by pre-rafting in compression.

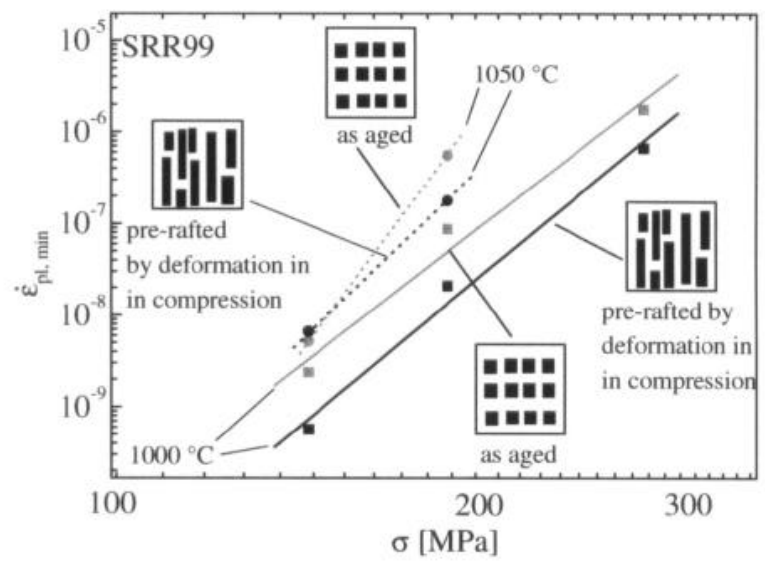

Fig. 18: Comparison of the minimum plastic creep rate of the initial cuboidal $\gamma / \gamma^{\prime}$-microstructure and the raft structure parallel to the stress axis at different temperatures $\left(1000^{\circ} \mathrm{C}, 1050^{\circ} \mathrm{C}\right)$ and different applied tensile stresses (150 - 300 MPa).

\section{Conclusions}

In the present work on the monocrystalline superalloy SRR 99, is was shown exemplarily that pre-rafting in compression is beneficial for the high-temperature creep strength. It is proposed that this conclusion will apply also to other monocrystalline nickel-base superalloys. The main result were as follows:

- Pre-rafting in compression is suitable to not only improve the isothermal fatigue strength, as shown earlier, but also the tensile creep strength.

- The observed enhancement of the creep strength is in good agreement with predictions based on the Peach-Koehler calculations of the rate-controlling dislocation climb force on vertical and horizontal $\gamma / \gamma^{\prime}$-interfaces.

- At a given temperature, the range of enhanced creep strength due to pre-rafting depends primarily on the applied stress, which determines the time available for microstructural transformations of the rafts introduced prior to the tensile creep test by a small compressive creep strain. 
- It is conceivable that the extent of the creep strain within which the creep strength can be enhanced could be extended by a suitable measure to stabilise the rafts lying parallel to the stress axis against transformation into rafts lying perpendicular to the stress axis.

\section{References}

1. T.P. Gabb, S.L. Draper, D.R. Hull, R.A. MacKay and M.V. Nathal, "The Role of Interfacial Dislocation Networks in High Tcmpcrature Crecp of Supcralloys", Materials Science and Engi neering, A 118 (1989), 59-69.

2. H. Mughrabi, W. Schneider, V. Sass and C. Lang, "The Effect of Raft Formation on the High-Temperature Creep Deformation Behaviour of the Monocrystalline Nickel-Base Superalloy CMSX$4^{\prime \prime}$, in Strength of Materials, Proc. ICSMA 10, eds. H. Oikawa et al., (Sendai: The Japan Institute of Metals, 1992), 705-708.

3. T.M. Pollock and A.S Argon, "Directional Coarsening in Nickel-Base Single Crystals with High Volume Fractions of Coherent Precipitates", Acta Metallurgica et Materialia, 42 (1994), 1859-1874.

4. S. Draper, D. Hull and R. Dreshfield, "Observation of Directional Gamma Prime Coarsening during Engine Operation", Metallurgical Transactions'A, 20A (1989), 683-688.

5. S. Kraft, I. Altenberger and H. Mughrabi, "Directional $\gamma-\gamma$ " Coarsening in a Monocrystalline Nickel-Based Superalloy During Low-Cycle Thermomechanical Fatigue", Scripta Metallurgica et Materialia, 32 (1995), 411-416, and Scripta Metallurgica et Materialia, 32 (1995), 1903 (Erratum).

6. A. Pineau, "Influence of Uniaxial Stress on the Morphology of Coherent Precipitates During Coarsening-Elastic Energy Considerations", Acta Metallurgica, 24 (1976), 559-564.

7. F.R.N. Nabarro, "Rafting in Superalloys", Metallurgical and Materials Transactions, 27A (1996), 513-530.

8. H. Biermann, B. von Grossmann, T. Schneider, H. Feng and H. Mughrabi, "Investigation of the $\gamma / \gamma$ ' Morphology and Internal Stresses in a Monocrystalline Turbine Blade after Service: Determination of The Local Thermal and Mechanical Loads", Superalloys 1996, Proc. of $8^{\text {th }}$ Int. Symp. on Superalloys, eds. R.D. Kissinger et al., (Warrendale, PA: The Minerals, Metals \& Materials Society, 1996), 201-210.

9. M. Ott, U. Tetzlaff and H. Mughrabi, "Influence of Directional Coarsening on the Isothermal High-Temperature Fatigue Behaviour of the Monocrystalline Nickel-Base Superalloys CMSX-6 and CMSX-4", in Microstructural and Mechanical Properties of Metallic High-Temperature Materials / DFG research report eds. H. Mughrabi et al., (Weinheim: Wiley-VCH, 1999), 425-440.

10. H. Mughrabi, M. Ott and U. Tetzlaff, "New Microstructural Concepts to Optimize the High-Temperature Strength of $\gamma$ '-Hardened Monocrystalline Nickel-Base Superalloys", Materials Science and Engineering, A234-236 (1997), 434-437.
11. P. Caron, P.J. Henderson, T. Khan and M. McLean, "On the Effect of Heat Treatments on The Creep Behaviour of A Single Crystal Superalloy", Scripta Metallurgica, 20 (1986), 875-880.

12. R.A MacKay and L.J. Ebert, "The Development of $\boldsymbol{\gamma}-\boldsymbol{\gamma}$ ' Lamellar Structures in a Nickel-Base Superalloy during Elevated Temperature Mechanical Testing", Metallurgical Transactions, 16A (1985), 1969-1982.

13. M.V. Nathal and L.J. Ebert, "Elevated Temperature CreepRupture Behaviour of the Single Crystal Nickel-Base Superalloy NASAIR 100", Metallurgical Transactions, 16A (1985), 427-439.

14. A. Fredholm and J.-L. Strudel, "High Temperature Creep Mechanisms in Single Crystals of Some High Temperature Performance Nickel Base Superalloys", in High Temperature Alloys: Their Exploitable Potentials, Proc. of Petten Int. Conf, eds. J.B. Marriot et al., (London: Elsevier Applied Science, 1987), 9-18.

15. J. Svoboda and P. Lukáš, "Model of Creep in <001>-oriented Superalloy Single Crystals", Acta Materialia, 46 (1998), 34213431.

16. W. Schneider, J. Hammer and H. Mughrabi, "Creep Deformation and Rupture Behaviour of The Monocrystalline Superalloy CMSX-4-A Comparison With The Alloy SRR 99, in Superalloys 1996, Proc. of $7^{\text {th }}$ Int. Symp. on Superalloys, eds. S.D. Antolovich et al., (Warrendale, PA: The Minerals, Metals \& Materials Society, 1996), 589-598.

17. W. Schneider, "Hochtemperaturkriechverhalten und Mikrostruktur der einkristallinen Nickelbasis-Superlegierung CMSX-4 bei Temperaturen von $800^{\circ} \mathrm{C}$ bis $1100^{\circ} \mathrm{C}$ " (Doctorate Thesis, Universität Erlangen-Nürnberg, 1993), 155-156.

18. J. Hammer, "Kriech-und Zeitstandsverhalten der einkristallinen Nickelbasis-Superlegierung SRR99 unter besonderer Berücksichtigung mikrostruktureller Vorgänge und der Materialfehler" (Doctorate Thesis, Universität Erlangen-Nürnberg, 1990), 149157.

19. H. Mughrabi, " $\gamma / \gamma$ ' Rafting and Its Effect on the Creep and Fatigue Behaviour of Monocrystalline Superalloys", in The Johannes Wecrtman Symposium, cds. R.J. Arsenault et al. (Warrendale, PA: The Minerals Metals and Materials Society, 1996), 267278.

20. D.D. Pearson, F.D. Lemkey and B. H. Kear, "Stress Coarsening of $\gamma$ ' and its Influence on Creep Properties of a Single Crystal Superalloy, in Superalloys 1980 , Proc. $4^{\text {th }}$ Int. Symp. Superalloys, eds. J. K. Tien et al., (Metals Park, OH: ASM, 1980), 513-520.

21. D.D. Pearson, B.H. Kear and F.D. Lemkey, "Factors Controlling the Creep Behaviour of a Nickel-Base Superalloy," Creep and Fracture of Engineering Materials and Structures, eds. B. Wishire and D.R.I. Owen, (Swansea: Pineridge Press, 1981), 213233.

22. C. Carry and J.-L. Strudel, "Apparent and Effective Creep Parameters in Single Crystals of a Nickel Base Superalloy - I. Incubation Period", Acta Metallurgica, 25 (1977), 767-777. 
23. A. Fredholm and J. L. Strudel, "On the Creep Resistance of some Nickel Base Single Crystals", in Superalloys 1984, Proc. of $5^{\text {th }}$ Int. Symp. on Superalloys, eds. M. Gell et al., (Warrendale, PA: Metallurgical Society of AIME, 1984), 211-220.

24. P. Caron and T. Khan, "Improvement of Creep Strength in a Nickel-Base Single-Crystal Superalloy by Heat Treatment", Materials Science and Engineering, 61 (1983), 173-184.

25. M.V. Nathal and R.A. MacKay, "The Stability of Lamellar $\gamma$ $\gamma$ 'Structures", Materials Science and Engineering, 85 (1987), 127138.

26. M.V. Nathal, R.A. MacKay and R. V. Miner, "Influence of Precipitate Morphology on Intermediate Temperature Creep Properties of a Nickel-Base Superalloy Single Crystal", Metallurgical Transactions A, 20A (1989), 133-141.

27. M. Ott and H. Mughrabi, "Dependence of the Isothermal Fatigue Behaviour of a Monocryst 3 iline Nickel-Base Superalloy on the $\gamma / \gamma^{\prime}$-Morphology", in Proc. of FATIGUE '96, eds. G. Luitjering and H. Nowack, (Oxford: Elsevier Science Ltd, 1996), 789794.

28. H. Mughrabi and U. Tetzlaff, "Microstructure and HighTemperature Strenghth of Nickel-Base Superalloys", in Advanced Engineering Materials, in print.

29. U. Tetzlaff, M. Nicolas und H. Mughrabi, "Can the High Temperature Tensile Strength of Nickel-Base Superalloys be Improved by pre-rafting?", in Proc. of EUROMAT '99, (Weinheim: Wiley-VCH, 2000), in print.

30. H. Mughrabi, H. Feng and H. Biermann, "On the Micromechanics of the Deformation of Monocrystalline Nickel-Base Superalloys", in Proc. of the IUTAM Symposium on Micromechanics of Plasticity and Damage of Multiphase Materials, eds. A. Pineau and A. Zaoui, (Dordrecht, Netherlands: Kluwer Academic Publishers, 1996), 115-122.

31. L. Müller, U. Glatzel and M. Feller-Kniepmeier, "Modelling Thermal Misfit Stresses in Nickel-Base Superalloys Containing High Volume Fraction of $\boldsymbol{\gamma}^{\prime}$ Phase", Acta Metallurgica et Materialia, 40 (1992), 1321-1327.

32. T.M. Pollock and A.S. Argon, "Creep Resistance of CMSX-3 Nickel-Base Superalloy Single Crystals", Acta Metallurgica et Materialia, 40 (1991), 1-30.

33. T. Link und M. Feller-Kniepmeier, "Elektronenmikroskopische Untersuchung von $\gamma / \gamma$-Phasengrenzen in der einkristallinen Nickelbasislegierung SRR 99 nach Hochtemperaturkriechen", Zeitschrift für Metallkunde, 79 (1988), 381-387.

34. M.V. Nathal, "Effect of Initial Gamma Prime Size on the Elevated Temperature Creep Properties of Single Crystal Nickel Base Superalloys", Metallurgical Transactions A, 18A (1987), 1961-1970. 